\title{
EJSBS
}

The European Journal of Social \&

Behavioural Science

ISSN: 2301-2218 (ONUINE)
OPEN ACCESS

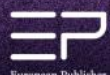

The European Journal of Social and Behavioural Sciences

EJSBS Volume XXX, Issue III (eISSN: 2301-2218)

\section{VULNERABLE MEDICAL STUDENT ECOSYSTEMS: TRANSDISCIPLINARY LEARNING SCIENCES INTERVENTIONS, MAXIMIZING STUDENT LEARNING AND PROMOTING MENTAL HEALTH}

\author{
Kevin Michael Watson ${ }^{\text {a* }}$ \\ ${ }^{a}$ Werklund School of Education, Department of Learning Sciences, University of Calgary,2500 University Drive \\ NW, Calgary Alberta, T2N1N4, Canada
}

\begin{abstract}
Medical students (MS), as a focus of investigation, are usually the last group that would be considered as suffering from mental health issues. However, the literature shows otherwise; MS suffer debilitating anxiety and depression which worsen with the progression of their studies. The literature also highlights the medical school curriculum as a significant cause of the elevated stress, anxiety, and depression levels within the MS population. This article explores the vulnerable nature of MS by focusing on the nature of the medical school's hidden curriculum and culture, highlighting its impact on the entire medical education ecosystem and the MS. This article, then, investigates the three dominant epistemological belief frames in medical school which impact the vulnerable nature of MS. Finally, this article presents potential interventions, targeting the need for cultural change that may contribute to the creation of a more compassionate learning ecosystem to build the MS' mental resilience in medical school and create a stronger medical workforce.
\end{abstract} practitioners

Keywords: Medical education, vulnerable ecosystems, lifelong learning, mental health, reflective

(C) 2021 Published by European Publisher. www.europeanpublisher.com

\footnotetext{
${ }^{*}$ Corresponding author.

E-mail address: Kevin.watson1@ucalgary.ca
} 
https://doi.org/10.15405/ejsbs.305

eISSN: 2301-2218 / Corresponding Author: Kevin Michael Watson

Selection \& Peer-review under responsibility of the Editors

\section{Introduction}

Medical students (MS) are not necessarily perceived to be an ecologically vulnerable community (Gutiérrez, 2016) in terms of socialization. This is often due to the social position, monetary affluence, and amount of formal academic schooling required to simply be admitted to medical school. However, MS are amongst one of the most vulnerable mental health populations worldwide. Studies indicate that stress is a significant element of MS life (Dyrbye et al., 2005; Rotenstein et al., 2016) and is an accurate predictor of debilitating anxiety and depression (Rotenstein et al., 2016) that increases as medical school progresses. A robust literature shows that stress, anxiety, and depression levels among MS greatly surpass the general population's approximate global prevalence of 5\% (Dyrbye et al., 2006, 2017; Rotenstein et al., 2016; Wilkes et al., 2019, World Health Organization, 2017), showing stress, anxiety, and depression having personal, social, academic, and professional impacts. This is reinforced by remarkably minimal MS who seek treatment (MacArthur \& Sikorski, 2020; Tjia et al., 2005). Rotenstein et al.'s (2016) meta-analysis of 195 studies indicates only $15.7 \%$ of MS seek help (Dyrbye et al., 2017; Slavin, 2018; Wilkes et al., 2019). The literature also implicates the medical school curriculum as a significant cause of the elevated stress, anxiety, and depression levels within the MS population (Dyrbye et al., 2017; Wilkes et al., 2019), including both the explicit curriculum and the implicit medical school culture. This implicit culture is referred to as the hidden curriculum (HC) (Ward \& Outram, 2016). It is clear from the literature that stress, anxiety, and depression among MS significantly impact their mental health.

The paper aims to illustrate how medical school knowledge frameworks have traditionally created a toxic $\mathrm{HC}$ that impacts MS mental health. While the $\mathrm{HC}$ and its knowledge frameworks produce technically proficient physicians and create a sense camaraderie, it also has the potential to undermine the holistic mental health of MS. This paper describes the medical schools' HC/culture, highlighting its reciprocal relationship between the medical education ecosystem and the MS. Second, it explores the vulnerable nature of MS that ultimately leads to vulnerable healthcare professionals. Third, it investigates the three dominant epistemological belief frames in medical school that are impacted by the vulnerable nature of MS. Last, this article highlights potential interventions, targeting the need for change. These interventions focus on the foundational development of Social Emotional Learning (SEL) and lifelong learning (LLL) community orientation and skillset that may contribute to the creation of a more compassionate learning ecosystem for MS. 
https://doi.org/10.15405/ejsbs.305

eISSN: 2301-2218 / Corresponding Author: Kevin Michael Watson

Selection \& Peer-review under responsibility of the Editors

\section{The Hidden Curriculum}

The Hidden Curriculum (HC), coined by Jackson, (1990), is the implicit socialization process that impacts any educational ecosystem. The $\mathrm{HC}$ forms the basis for the enculturation of MS into the Medical Doctor (MD) brother/sisterhood through a structured educational ecosystem of community indoctrination. MS matriculating into medical schools expect to learn the explicitly taught curriculum (e.g., anatomy, physiology; pathology); however, what is unexpected is the $\mathrm{HC}$ which impacts the MS mindset, learning orientation, and self-perceived competence towards academics and self-care. This type of fraternity enculturation is comparable to military training, which emphasizes surreptitiously targeting and eliminating weaker members, as opposed to guiding or mentoring compassionate healers (DiRosa \& Goodwin, 2014). This runs contrary to the humanistic Hippocratic Oath (HO) (Jones, 1945) that was founded in Science, Technology, Engineering, and Mathematic (STEM) Knowledge Frames (KF) from fifth century Greece. The HO espouses the basic principle to simply: Do no harm. Despite its permanence in the MS academic vernacular, the HO premise is not considered an essential KF for academic success in medical school training (Gagarin \& Fantham, 2010).

The literature establishes that stress, anxiety, and depression among MS can become a persistent disorder extending into a physician's professional career (Dyrbye et al., 2006, 2014). For example, physicians are vulnerable to burnout, empathy fatigue, suicide ideation, and other social disorders that may lead to poor patient care (MacArthur \& Sikorski, 2020). MS and physician mental health issues parallel the continuum of psychosis theory (DeRosse \& Karlsgodt, 2015; Linscott \& van Os, 2010) culminating in schizophrenia on the extreme end and hallucinations and delusions of varying degrees of severity and prevalence. MS mental health issues also exhibit varying degrees of severity and a variety of manifestations, such as maladaptive perfectionism (MP) and Imposter Syndrome (IS) (Hu et al., 2019) with substance abuse and suicide at the severe end. It is clear that MS mental health vulnerability can significantly impact not only the student/future doctor (MacArthur \& Sikorski, 2020) but also patients, communities, and society.

\subsection{The Hidden Curriculum and Student Frames of Mind}

Often, MS have idealistic perceptions regarding the rigours of the medical school culture and becoming a physician. The MS ecosystem intertwines the social learning environment with informal frames of knowledge. It is informally developed through the system of traditional institutional influences. These covert influences impact the learner's skillset (Gofton \& Regehr, 2006; Hafferty, 1998; Lempp \& Seale, 2004; Paice et al., 2002). 
https://doi.org/10.15405/ejsbs.305

eISSN: 2301-2218 / Corresponding Author: Kevin Michael Watson

Selection \& Peer-review under responsibility of the Editors

Jarvis (1999) terms an individual's skillset, a Biography (knowledge, skills, attitudes, values) (in-depth description of biography below).

In addition to assessing content knowledge and skills, MS attitudes are also scrutinized within the medical school ecosystem. The HC ecosystem clandestinely transmits knowledge through the instructors/supervisors. Instructors professionally mentor and assess the learner's ability to fit into the traditional culture of the ecosystem and their suitability to be a physician. This ecosystem emphasises hierarchical power-relationships (blind adherence), privilege (brownnosing, boot-licking), rites-of-passage (bullying and fear-based teaching), and a customary sense of invulnerability and indestructability (Mackin et al., 2019). These elements lay the foundation for a vulnerable ecosystem, creating dependency-based KF beliefs within MS mindsets. These beliefs metastasize like cancer to MS mindsets about academics, wellness, career prospects, and holistic learning (Mackin et al., 2019; Paice et al., 2002).

These beliefs often extend to hiding social issues (drinking or drug use) (Boon \& Turner, 2004), and stigmatise asking for help (refusing assistance and dependence on the culture itself) (Boon \& Turner, 2004). It is this dependence that makes MS vulnerable and malleable through the structured hierarchies, promoting a high external locus-of-control mindset (Rotter, 1966) (i.e., belief that success is beyond their control). This potentially creates strong feelings of helplessness that can lead to a variety of concerning academic and social behaviours. These behaviours cater to the $\mathrm{HC}$ and build professional identities and mindsets comprising: (1) a powerlessness to decline time requests at the risk of appearing vulnerable, (2) continual fear-based volunteering (taking on new fraternity roles) regardless of personal health/wellness, (3) status/reputation-based hierarchical decision-making, and (4) academic competition over social cooperation (Mackin et al., 2019; Ward \& Outram, 2016). This runs contrary to self-directed learning (Knowles, 1975) mindsets that could potentially lead to foundational LLL and self-care. For MS who are immersed within their community, the HC ecosystem is inescapable and displays a personal deterioration of idealism, a taken-for-granted professional identity, compromising attitudes to hierarchy, compliant ethical values/moral compass, and anaesthetized sensations and emotions to self and others (Lempp \& Seale, 2004).

The most brutal aspect of the MS experience is towards those who resist it. MS and physicians who strive for a work-life balance, or show vulnerability (e.g., illness; self-directed questioning; support-seeking behaviours) can be shunned and ostracized. On the contrary, this culture rewards uncompromising standards, perfectionism, and prioritization of the MD identity and work above everything else (Ward \& Outram, 2016). Mahood (2011) purports that this vulnerable ecosystem and KF construct "ethical chameleons" (p. 984) who modify their core values through triage to attain status within the culture. Although rigorous standards 
https://doi.org/10.15405/ejsbs.305

eISSN: 2301-2218 / Corresponding Author: Kevin Michael Watson

Selection \& Peer-review under responsibility of the Editors

are undisputed for physicians to ensure competency, further research interventions are needed to understand the mental health challenges facing MS in attaining such standards.

\section{Medical Students as a Vulnerable Ecosystem and Community}

It is clear MS are a vulnerable ecosystem. MacArthur \& Sikorski (2020) clearly identify that MS, and ultimately physicians, are a particularly vulnerable segment of the population. They state that:

exacerbating the prolonged stress that characterizes medical school is that the adverse effects of stressors are not mitigated by health-promoting behaviors, as medical students tend to engage in unhealthy behaviors regarding diet, caffeine, nicotine, alcohol/drugs, physical exercise, and sleep. They also face barriers to seeking mental health treatment, most notably stigma. With physicians dying by suicide at a rate nearly twice that of the general population... more attention needs to be paid to the early risk factors of poor well-being. (p. 2)

The vulnerability of MS who eventually become at-risk physicians needs to be considered early in medical school. This begins with the simple recognition that MS are vulnerable. What makes MacArthur \& Sikorski's (2020) statements particularly concerning is the lack of general awareness in society that physicians are so vulnerable. Generally, individuals consider physicians only in a professional context when they personally need medical attention.

MS put their mental health at risk to survive the training. It should at least be concerning that MS and ultimately future physicians must become, as quoted above by Mahood (2011), "ethical chameleons" to succeed in medical school. In addition, since this issue is multifactorial, it is clear that future interventions and research need a balanced approach (ChewGraham et al., 2003; Mackin et al., 2019; Mahood, S, 2011; Paice et al., 2002). Starting early in medical school, this balanced approach must include foundational LLL skills (e.g., resilience; critical thinking; integration; growth mindset). LLL should align with medical KF and skills content (Cornford, 2002). This is evidenced by Sockalingam et al (2017) who found that learners come out of the first phase of medical school into residency lacking solid LLL orientations and skills. As a result, both LLL and medical content must be initiated early in medical school to avoid putting MS in a vulnerable state. 
https://doi.org/10.15405/ejsbs.305

eISSN: 2301-2218 / Corresponding Author: Kevin Michael Watson

Selection \& Peer-review under responsibility of the Editors

\section{Knowledge, Tacit Knowledge, and Epistemological Frames for MS}

\subsection{Knowledge-General}

In order to understand and address the $\mathrm{HC}$ of medical schools, it is critical to define and discuss knowledge. Knowledge is defined as "the information, understanding and skills that you gain through education and experience" (Oxfordlearnersdictionary, 2020). Having a working definition of knowledge is fundamental to the discussion about the HC and community because it emphasizes the relationship between "education" and "experience". Supporting mental health and learning interventions within the MS ecosystem requires a synergy between both education and experiences.

First, educational ecosystems are created to function effectively through a deliberate synergy between theoretical course/curriculum content knowledge, and practical operationalization of content knowledge. Any educational ecosystem requires critical integration, continuity, and engagement knowledge indicators. These indicators should entail examining procedural understanding and synthesis within the specific ecosystem. This is particularly true in ecosystems focused on professional occupational outcomes (e.g., Medical Education). These indicators are created, taught, and assessed through that ecosystem's specific professional lens.

In the case of medical school, the creation, teaching, and assessment of knowledge all function as a controlling matrix for the HC. Medical educators are predominantly professionals from the field who have all experienced the MS ecosystem as graduated medical doctors. In many cases, educators (at all levels) with no formal teacher training, who have been successful within a particular ecosystem, tend to teach the way that they were taught (e.g., high-school, military training, professional schools of education). Considering this statement, it serves to reason that the instructors/mentors who have experienced MS training and understand the physician career path, often function to reinforce the HC. While both content and practical knowledge are critical of education, in MS training and the procedural mentorship process, instructors often create intentional confusion about what knowledge is most important to learn.

Knowledge Frames (KF) of belief require a level of learner confidence about the validity and value of knowledge within their current sociocultural ecosystem. Lack of KF confidence can cause knowledge confusion for MS. This is the result of three interrelated variables within the MS ecosystem. Medical schools have a high operational tempo that is intensified by an extremely high knowledge volume, leading to significant MS cognitive load. The high operational tempo and the high volume of content are crammed into pressureoriented assessment time constraints. This trifecta of factors combined with the HC creates a community that normalises stress, anxiety, and depression. Therefore, MS and the medical 
school culture create knowledge beliefs that compartmentalize knowledge to be acquired into either high yield or superfluous/redundant. This places many MS into potentially distressful thinking patterns because they are always in survival mode as they are unclear about which curricular content is relevant or not. This lack of clarity creates a frenetic back-and-forth mindset that cultivates, maintains, and intensifies MS stress and anxiety, leading to a dependency on the ecosystem and $\mathrm{HC}$ itself.

\subsection{Experiential learning and MS General Knowledge}

The "experience" of gaining knowledge shows the critical nature of practical experiential learning knowledge development. Experiential learning (Boud et al., 1985; Dewey, 1933; Jarvis et al., 2003; Kolb, 1984) identifies the need to actively engage in social world experiences. These social world experiences formulate a foundational reference system that Jarvis et al. (2003) term a person's Biography. This biography is a collection of an individual's learning experiences and represents their current level of knowledge, skills, and attitudes that interacts with an individual's personal value and belief system. Essentially, a biography is the learning repertoire that each individual "brings to the table" within each and every social learning experience. Extending from Dewey (1933), Kolb (1984), and Boud et al. (1985), Jarvis et al. (2003) has postulated experiential learning based on four routes or choices, (non-learning; memorization; reflection; action) (see Table 1).

Table 1. Four routes of learning (Based on Jarvis, 2003)

\begin{tabular}{clll}
\hline Route & \multicolumn{1}{c}{ Label } & \multicolumn{1}{c}{ Description } & Reference to figure 1 \\
\hline 1 & Non-learning & $\begin{array}{l}\text { The learner rejects the learning } \\
\text { opportunity } \\
\text { The learner simply memorizes } \\
\text { information. }\end{array}$ & See box 4 in Figure 1 \\
& $\begin{array}{l}\text { Non-reflective } \\
\text { learning }\end{array}$ & See box 6 in Figure 1 \\
3 & Reflective learning & $\begin{array}{l}\text { The learner reflects on the } \\
\text { experience and learns } \\
\text { The learner practices what they } \\
\text { learned and have the option of both } \\
\text { reflective or non-reflective }\end{array}$ & See box 5 in Figure 1 \\
\hline
\end{tabular}

These routes form the basis of each learner's abilities to operationalize one's biography. To that end, Jarvis et al. (2003) highlights that learning is a critical "bridge between the world and the self, so that the self is not immune from the changes that are happening in the world at any time" (p.15). Stated simply, no student is completely detached from their learning 
ecosystem or the KF that govern the community. Considering, Jarvis' four routes of learning (see Table 1 and Figure 1.), large numbers of MS get stuck simply bridging between routes one and two mentioned. This is often referred to as bulimic learning (Zorek et al., 2010), where students memorize information and then regurgitate it during formal exams. While bulimic learning is not exclusive to medical school, it is intensified by the HC and is often what MS use as the basis of their study process and consider memorization as the sole mode of learning.

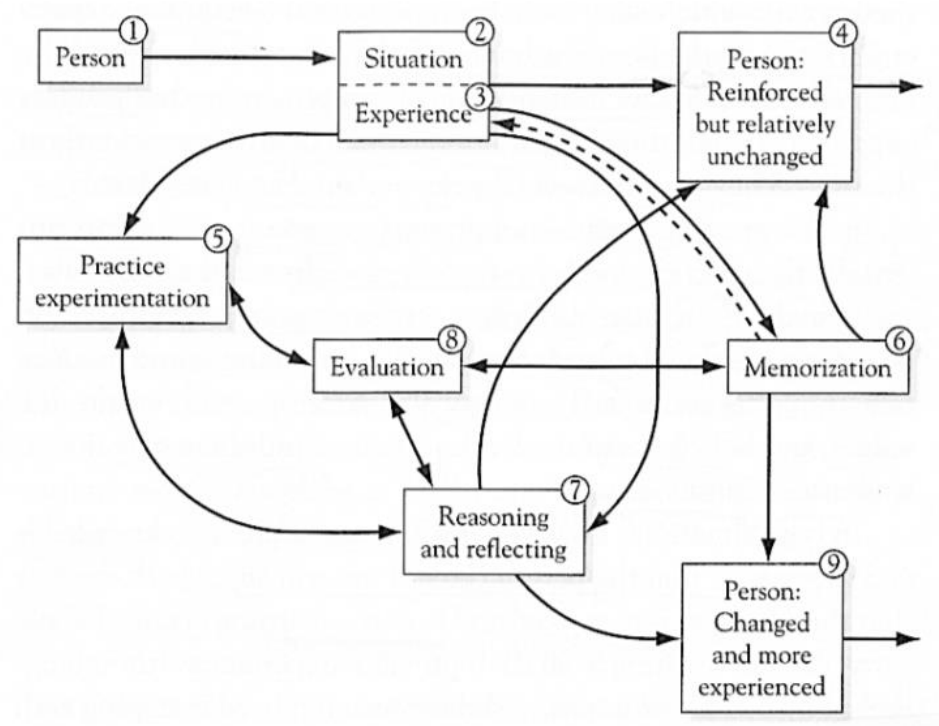

Figure 1. Jarvis's model of the learning process (4 routes of learning)

\subsection{Experiential learning, metacognition and the integration of knowledge}

In order to effectively operationalize Jarvis" "bridge" as a holistic learner, learners need to have the ability to metacognitively monitor and control (Flavell, 1979; Winne, 1996) their own development through a back-and-forth process. This process begins with the selfregulating mindset to leave the comforts of one's "habitus" (Bourdieu, 1990) (i.e., comfort zone) and to challenge one's biography through experiences. The key element to successful experiential learning is to operationalize choice within all four of Jarvis' experiential routes. Choice includes the recognition of autonomy and agency (Vygotsky, 1978) within the learning process. However, as evidenced above, the HC is resistant to emancipation of the learning process. It is a paradox of sorts with self-regulating messages being espoused in the ether, but pragmatically, the more traditional type of didactic instruction dominates. This aligns with Freire's (1996) contention that education is either about emancipation or control. Medical schools promote the former, but generally practice the latter. 
In the current generation, the lack of foundational LLL orientation and skill development is developing learners who are often fragile and have what teachers may consider to be "maladaptive schemas" towards holistic development. A schema is understood in cognitive science as dynamic, unified, and integrated structures of organization for knowledge of subjects, or events (Bartlett, 1995). Schemas are built through experience and are culturally mediated (Piaget, 1976). In the current educational and societal landscape, student schemas represent their everyday experiences and their normal organization and understanding of experiential knowledge. Recent years have seen a shift away from large cultural Set Social Mechanisms (SSM) (Gross et al., 2009), and an emphasis towards snow-plowing challenges from students in attempts to accommodate individual identity and experiences. However, learners devoid of variegated experiences and true struggle, often do not have resilience to persevere or the mental capacity to overcome adversity. This ultimately has developed a generation of students whose schemas are less resilient, less group minded, have less selfregulated learning skills, and less consideration of others. (i.e., Theory of Mind). In the MS context, maladaptive schemas (Bartlett, 1995) about learning are dominated by rigid KF and HC. Thus, in the MS controlled ecosystem, the explicit curriculum, the HC, and the instructional set up determine the amount of autonomy and agency that learners can operationalize. Therefore, the choice of learning route is stifled leading to LLL being limited.

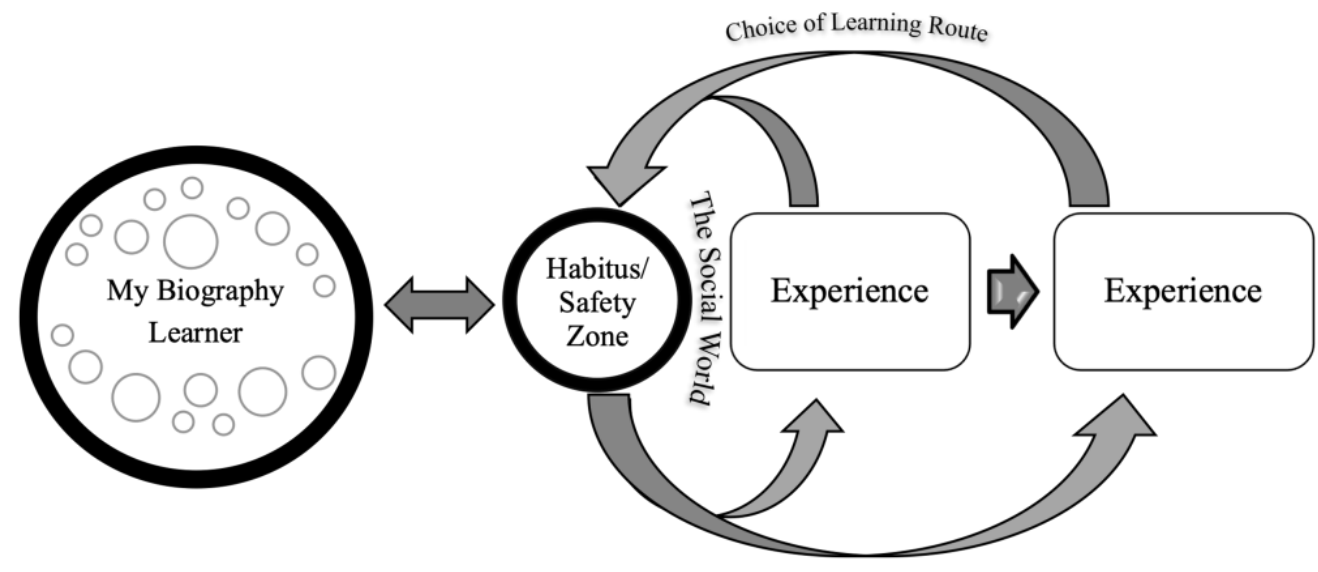

Figure 2. Biography and Habitus Operationalized in the Experiential Learning Process

Returning to Jarvis and experiential learning, each learners biography should include the ability to choose to reflect or simply act if needed (Jarvis Routes 3 and 4; See Table 1 and Figure 1). Ideally, individuals should have the choice of routes three or four; however, this requires skilfull learner development that focuses on reflective and active practice. In recent 
years, teaching and learning centres have been established in medical schools to assist learners on how to maximize all four routes (see Figure 1). Unfortunately, it is difficult to undo years of conditioned learning that focused on memorization and test-taking, starting in high school and often reinforced in undergraduate studies. Neuroscience and psychology research (Owens \& Tanner, 2017; Tokuhama-Espinosa, 2017, 2019) has established a connection between the plasticity of experiential learning, teaching, and social cognition. This combination impacts the KF of each learner and the development of the learner's biography. Thus, each experience within an ecosystem can be intertwined through teaching, mentorship, and learning.

\subsection{Tacit Knowledge}

Tacit knowledge (TK) is the next critical consideration. TK is a vital aspect of any professional or educational ecosystem as it is not easily codified. While ubiquitous learning and knowledge is prevalent throughout social life, humans have the cognitive and social architecture (Bless \& Greifeneder, 2017) to manage both the explicit and implicit nature of knowledge. That stated, once a formal learning environment (externally controlled educational environment) is entered, the structured and encultured ecosystem includes parameters and specific "ways of knowing", requiring adaptation and change.

In the MS experience, professional ways of knowing are implicated specifically in the vulnerable nature of MS learning and interactions. Not all structured and designed knowledge (e.g., educational ecosystems) are framed around any discourse or narrative, so tacit experiences of knowledge acquisition should be considered. In defining the tacit dimension of knowledge, Polanyi (1983) simply states "we know more than we can tell" (p. 4) which refers to intuitive knowledge that cannot be necessarily verbalised or coherently narrativised. Therefore, much of the development of TK requires situated learning experiences. This is where enculturation can positively and negatively impact educational environments.

Along this vein, Collins (2007) extends Polanyi's definition to add a more situated experiential view by stating "The concept of tacit knowledge lives rich, varied and... independent lives in different academic worlds." (p. 257) Medical school is a perfect example of those professional academic worlds. Phrased another way, the medical school ecosystem is a situated set of social experiences that not only survives based on the inculcation of TK, but also thrives based on it. On the negative end, this ecosystem withstands, and resists change due to the same TK. For example, despite medical schools being aware that students are atrisk, Slavin (2016) contends that TK has caused eight decades of resistance to change as many professionals in the field consider changes to be a "softening of the culture and students" ( $p$. 2195). In particular, the social collectivism in medical school is a driving force behind the 
https://doi.org/10.15405/ejsbs.305

eISSN: 2301-2218 / Corresponding Author: Kevin Michael Watson

Selection \& Peer-review under responsibility of the Editors

current KF that dominate the MS experience both explicitly and implicitly. Collins (2007) contends the "taken-for-granted... collective tacit knowledge" (pp. 258) within a science environment impacts the social collectivism. Conversely, it is also the inescapability, covert transmission, and the resistance to change that makes the collectivism such an integral contributor to the vulnerability of the MS ecosystem.

\section{Medical School Epistemological frames}

Goffman (1997) introduced and defined the concept of KF, designating how individuals initiate, develop, and maintain, or even change expectations. These KF assist individual sensemaking required to navigate complex social spaces and ecosystems. Three frames of content and process knowledge are acknowledged in the MS experience: (1) medical sciences; (2) clinical skills; and (3) professionalism that require rationalist, empirical, and pragmatic understanding in order to create a legitimate professional body of knowledge, or medical doctor "ways of knowing” (Scheffler, 1965)

Epistemologically, MS develop deep and rich knowledge of medicine but the mental health cost of this development is a concern. Initially, MS lose their beliefs and idealistic views of becoming knowledgeable and compassionate healers. That idealism is often replaced with KF beliefs and their biographies are focused solely on compartmentalized knowledge. Instead of integrating all three KF to create a solid foundation, learners leap from one KF to another; essentially hoping to fill in their greatest knowledge gap. There is substantial emphasis on each individual KF with minimal time and mental energy to integrate. This jumping from KF-toKF feeds into the fear MS have due to the uncertainty of what knowledge is needed. Unfortunately, the lack of integration contributes to the vulnerability of the MS ecosystem. As MS graduate to become doctors through the MS ecosystem, they must now function within the physician ecosystem. However, moving through these ecosystems and the corresponding KF is accompanied with significant mental health costs (Hu et al., 2019; Slavin et al., 2014).

\section{Sociocultural Lens}

The discussion of general knowledge, tacit knowledge, and epistemological frames in the context of the MS as a vulnerable group, naturally situates itself within the sociocultural lens. Using the sociocultural lens as a foundation of knowledge and considering MS vulnerability to mental health issues requires considering MS experience internally and externally. In support, Vygotsky (1978), who specifically investigated children, purports "every function in the child's cultural development appears twice: First on the social level and later on the individual level” (p. 57). Considering Vygotsky's (1978) contention in the context 
https://doi.org/10.15405/ejsbs.305

eISSN: 2301-2218 / Corresponding Author: Kevin Michael Watson

Selection \& Peer-review under responsibility of the Editors

of the MS experience, internalizing social relationships at the individual level could account for aspects of MS vulnerability. For example, the medical school ecosystem is traditionally and historically oppressive. If an individual's continuing professional development depends on both their individual internalization of their social relationships and the epistemological frames that govern those relationships, it would be difficult not to internalize an oppressive social culture (e.g., sports cultures; political movements such as the Nazis).

Intense sociocultural environments require individuals to adapt one's own beliefs and identity to match expectations of success within that environment. Adapting to the MS educational experience can evoke feelings of helplessness and this demonstrates one of the challenges of learning in a vulnerable ecosystem. For example, Wenger (1998) states that "situated learning is as much a part of human nature as sleeping or eating, that it is both life sustaining and inevitable, and that - given a chance - we are quite good at it" (p. 15). Within a positive learning culture, positive outcomes during internalization naturally occur. On the other hand, learners who are situated within a negative learning culture can internalize negative outcomes just as naturally. This is common in medical school as MS attempt to adapt to being part of that ecosystem. Despite MS being in school by choice, many feel helpless to remove themselves from the ecosystem out of a sense of invincibility that is facilitated in medical school. Additionally, many MS tend to lose their previous identity from their pre-medical school lives. Yet, they tend to retain their memorization learning mindset as learning is generally not a component of the medical curriculum. The identity development of becoming a professional is natural and part of MS development into professional physicians. It is the mental health side effects that require early and coordinated learning interventions in order to maximize the KF development of the medical education content and to maximize the plasticity of the brain in terms of learning.

\section{Interventions and Lifelong Learning: Rationale; Research; Interventions}

\subsection{Rationale for Transdisciplinary Learning Sciences Approaches}

The Learning Sciences field emphasizes transdisciplinary-based intersection points and innovations through formal and informal real-world learning (e.g., neuroscience; psychology; education; learning; technology; sociology). As evidenced throughout this article, research indicates the root cause of dangerously elevated MS stress, anxiety, and depression, leading to vulnerable students and an overall vulnerable ecosystem, is multi-factorial. These factors implicate the explicit and implicit curricula, and impact MS' knowledge, social interaction, and the overall learning environment. (Rotenstein et al., 2016; Slavin, 2018). As stated above, MS culture is similar to military training. It emphasizes MS who can hack it and ultimately 
https://doi.org/10.15405/ejsbs.305

eISSN: 2301-2218 / Corresponding Author: Kevin Michael Watson

Selection \& Peer-review under responsibility of the Editors

make it, compared to those who cannot and drop out (DiRosa \& Goodwin, 2014). This mentality emphasizes the Darwinian, survival of the fittest, mentality as opposed to mentoring empathetic physicians and compassionate students. Therefore, exploring a multifactorial approach from a Learning Sciences perspective is prudent.

In terms of MS stress, anxiety, and depression, it would appear that mental health issues may continue to exist and could get worse for MS as generations move forward if issues are not addressed in an integrated way. One clear option is to integrate all three parallel tenets of the research literature (MS and physician literature). These tenets each call for adjustments to (1) medical school culture change, (2) MS stress, anxiety and depression reduction, and (3) medical school LLL orientation (mindset) and skillset. In order to deal with this multi-factorial issue, transdisciplinary Learning Sciences with a focus on integrating learning with content, is a viable option but requires researchers in all three areas to break traditional myopic research methods and to collaborate.

\subsection{Integrated Research Needs}

Within the literature, there are questions regarding what and how interventions should investigate solutions to this particularly vulnerable demographic. Largely, studies focus on self-report measures to identify stress, anxiety, and depression levels. Other studies have investigated single-factor curricular interventions (e.g., resilience training) (Dyrbye et al., 2017). Currently, no single-factor intervention study has reaped positive results that create resilience or develop less vulnerable students and physicians. Over the past two decades, medical education literature has published simultaneous yet compartmentalized issues within the field. These issues are: (1) culture changes to the medical school environment and curriculum (Hill et al., 2018; Lieff \& Albert, 2012; Mahood, 2011; Murakami et al., 2009; Sood et al., 2011, 2014; Ward \& Outram, 2016), (2) development of greater LLL orientation and operational skillsets as a central part of MS training (Hojat et al., 2003, 2009; Marzo, 2018; Mi \& Halalau, 2016; Sockalingam et al., 2017, 2019; Teunissen \& Dornan, 2008; Wetzel et al., 2010), and (3) reductions in MS stress, anxiety, and depression (Dyrbye et al., 2014; Rotenstein et al., 2016; Slavin et al., 2014; Slavin, \& Chibnall, 2016; Tjia et al., 2005). At a glance, each of these elements appears to have intersect points to the development and influence of the HC throughout the training of physicians. The vulnerable nature of this ecosystem community could benefit from research with a transdisciplinary Learning Sciences (Nathan \& Alibali, 2010; Sawyer, 2008) perspective.

To date, only Slavin et al. (2014) have investigated and successfully implemented a multi-factorial intervention approach. (Slavin \& Chibnall, 2016; Slavin, 2016; Slavin et al., 
2014; Slavin, 2018). However, studies such as this are rare and difficult to implement. Slavin, et al. (2014) implemented a seven-year longitudinal cohort study that incorporated a curricular culture change and reported reductions in MS stress, anxiety, and depression that was on par with global prevalence without reductions in academic quality. Slavin et al. (2014) added yearly independent variables to their curricular change through the pre-clinical stages of the education. However, it is unclear if these changes were simply a result of the environment that they created. Slavin et al.'s (2014) data, with follow up reports by Slavin \& Chibnall (2016) and Slavin (2018), has been limited to their individual school ecosystem. Replication studies both at the clinical level and follow ups with physicians in their practice would be prudent next steps. Slavin et al.'s (2014) study appears to have taken a Learning Sciences-like approach by lending from education, psychology, learning, and neuroscience in the curricular and culture change choices (e.g., moving to PASS/FAIL; reducing Anatomy coursework by ten percent; creating informal learning communities). Slavin et al. (2014) also attempted to reduce the vulnerability of the ecosystem through various optional Buddhist principles (e.g., Mindfulness courses).

While Slavin et al. (2014) appear to have unified culture change and mental health issues through several independent variables, the next logical variable to integrate would be holistic LLL orientation and skill development in medical school. Replicating Slavin et al.'s (2014) study with the additional variable of LLL could serve as a foundational intervention, beginning at matriculation and integrating the competencies from the first semester of medical school. This first step could be followed with other independent confounding variables that would impact MS stress, anxiety, and depression levels and the HC. Ultimately, as future physicians, current medical students will be expected to adapt to rapidly changing environments, not only considering their own well-being but also to consider each patient's needs (Mi \& Halalau, 2016). LLL orientation and skills include continual learner development, adaptations, social interactions, cognition and metacognition, resilience, self-initiation, and the appraisal of personal learning needs (Marzo, 2018). This would fit into current medical education competency-based curriculum changes.

\subsection{Multi-factorial Interventions including Lifelong Learning}

Medical school literature does urge the incorporation of LLL skills into the curriculum (Hojat et al., 2003, 2009; Marzo, 2018; Teunissen \& Dornan, 2008; Wetzel et al., 2010). In fact, the Association of American Medical Colleges and the Royal College of Physicians of Canada have LLL written into their core competencies (Chen et al., 2015; Frank et al., 2015). Literature has already produced robust research studies and reports that independently identify 
the need for LLL skills (Schumacher et al., 2013; Sockalingam et al., 2017; Wetzel et al., 2010). Unfortunately, Sockalingam et al (2017) indicate that upon entering residency, LLL orientation and LLL skills among MS are lacking. Clearly, there are issues surrounding the implementation of LLL. Medical schools need to implement LLL early in the curriculum (i.e., basic medical sciences). Along these lines, Hargreaves (2016) contends that physicians and MS are both learners and should work together in order to promote the inculcation of LLL orientation and skills. This includes considering intersection points between professional reflective practitioner development, neuroscience and psychology, experiential learning and holistic LLL. Additionally, holistic MS development would be at the heart of the multifactorial process (see Figure 3). The process of learning and its component parts would be taught in conjunction with medical school content and professionalism.

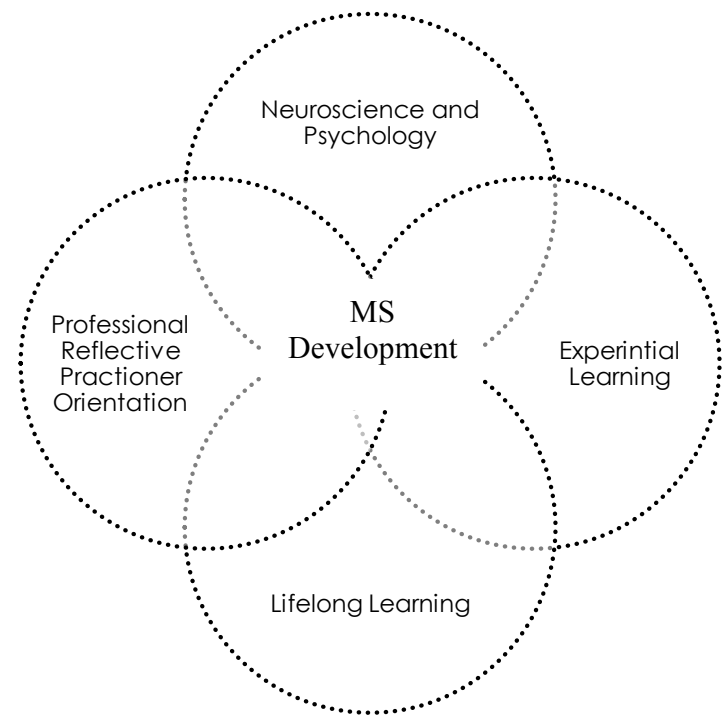

Figure 3. (Source Author) MS at the heart of combined learning influences

Further in-depth consideration reveals that adapting MS culture and KF to include experiential LLL with content could change the MS ecosystem and ultimately serve to protect MS' and future physicians' mental health. As stated above, teaching and learning centres have recently been established in medical schools, but they are most often utilized as band aids that focus on short-term study strategies (e.g., flashcards; study resources; technology apps) as opposed to mentoring foundational LLL orientation and skills (e.g., metacognitive control and monitoring, self-directed learning, growth mindset, reflective practitioner development; continuing professional development (CPD)). 
Following an integrated model focuses holistic mental health mentorship interventions towards awareness at the macro level. Considering Figure 4, MS need to be mentored on how to micro focus on the medical sciences content and then, have the appraisal and awareness to balance intense study with the expansive macro-focus on holistic development through LLL orientation and skills. This process, through immersion and threaded models of curriculum design (Watson, 2019) would also incorporate Jarvis' (2003) four routes of experiential learning; ultimately, engaging in back-and-forth process highlighted in Figure 2.

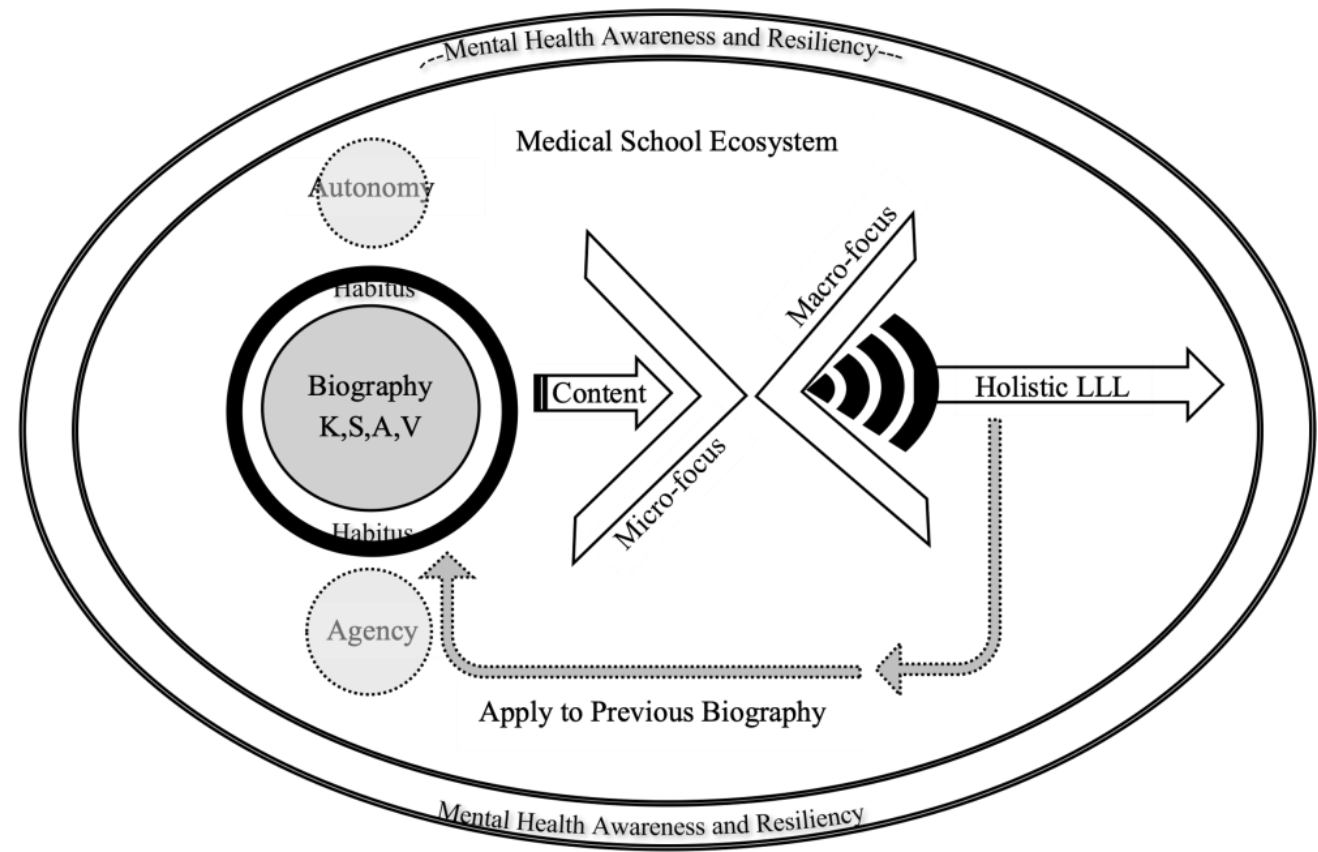

Figure 4. (Source: Author) Micro-focus; Macro focus Balance of Lifelong Learning for MS

If curricular interventions were planned in this way, the medical school ecosystem could remain intact but add the critical and often overlooked process of LLL. The process would allow learners to focus on professional development and macro aspects of holistic development, while focusing on the micro aspect of the medical sciences content (see Figure 4). It must always be the goal of educational programs to put the students in the best position to be successful. This can be maximized by ensuring foundational LLL skills are a key component of the learner's biography in synergy with curricular content and HC knowledge and skills. 
https://doi.org/10.15405/ejsbs.305

eISSN: 2301-2218 / Corresponding Author: Kevin Michael Watson

Selection \& Peer-review under responsibility of the Editors

\section{Conclusion}

The vulnerable MS ecosystem that is the result of the interplay between the medical school hidden curriculum/culture, explicit academic coursework, KF (e.g., tacit knowledge), and KF beliefs requires interventions focusing on transdisciplinary integration. Interventions to address this concern, at both the student level and the physician level, necessitate the implementation of multi-factorial changes to the MS environment and their learning experience. There does not appear to be a simple solution. The compartmentalization of the medical school curriculum (HC vs the explicit curriculum) runs parallel to the medical school research divide. This limits potential study interventions to improve MS mental health and vulnerability issues in the population. Ultimately, integration within the curriculum and within medical school research needs to come to the forefront. Each research field (culture change; LLL and MS mental health) in the literature need to be de-compartmentalized from their parallel silos and, through integrated interventions, analyze the entire MS experience through scholarly investigation to alleviate the vulnerable ecosystem or, at minimum, start to make progress towards confident reflective practitioners. Overall, this focus has the potential to build resilience, and potentially cause less vulnerability within the student population and in the medical field.

\section{Acknowledgements}

The author(s) declare that there is no conflict of interest.

\section{References}

Bartlett, F. C. (1995). Remembering. A Study in Experimental and Social Psychology. Cambridge: Cambridge University Press. https://doi.org/10.1017/CBO9780511759185

Bless, H., \& Greifeneder, R. (2017). Introduction: What is social cognition research about? Social Cognition: How Individuals Construct Social Reality, Second Edition, 1-15. https://doi.org/10.4324/9781315648156

Boon, K., \& Turner, J. (2004). Ethical and professional conduct of medical students: Review of current assessment measures and controversies. Journal of Medical Ethics, 30(2), 221-226. https://doi.org/10.1136/jme.2002.002618

Boud, D., Keogh, R., \& Walker, D. (1985). What is reflection in learning. Reflection: Turning Experience into Learning, 7-17.

Bourdieu, P. (1990). The logic of practice. Stanford university press.

Chen, H. C., van den Broek, W. E. S., \& ten Cate, O. (2015). The case for use of entrustable professional activities in undergraduate medical education. Academic Medicine, 90(4), 431-436. https://doi.org/10.1097/ACM.0000000000000586 
Chew-Graham, C. A., Rogers, A., \& Yassin, N. (2003). "I wouldn't want it on my CV or their records": Medical students' experiences of help-seeking for mental health problems. Medical Education, 37(10), 873-880. https://doi.org/10.1046/j.13652923.2003.01627.x

Collins, H. (2007). Bicycling on the moon: Collective tacit knowledge and somatic-limit tacit knowledge. Organization $\quad$ Studies, 28(2), 257-262. https://doi.org/10.1177/0170840606073759

Cornford, I. R. (2002). Learning-to-learn strategies as a basis for effective lifelong learning. International Journal of Lifelong Education, 21(4), 357-368. https://doi.org/10.1080/02601370210141020

DeRosse, P., \& Karlsgodt, K. H. (2015). Examining the Psychosis Continuum. Current Behavioral Neuroscience Reports, 2(2), 80-89. https://doi.org/10.1007/s40473-0150040-7

Dewey, J. (1933). How We Think: A Restatement of the Relation of Reflective Thinking to the Educative Process Vol. 8.

DiRosa, G. A., \& Goodwin, G. F. (2014). Moving away from hazing: The example of military initial entry training. Virtual Mentor, 16(3), 204-209. https://doi.org/10.1001/virtualmentor.2014.16.3.msoc1-1403

Dyrbye, L. N., Shanafelt, T. D., Werner, L., Sood, A., Satele, D., \& Wolanskyj, A. P. (2017). The Impact of a Required Longitudinal Stress Management and Resilience Training Course for First-Year Medical Students. Journal of General Internal Medicine, 32(12), 1309-1314. https://doi.org/10.1007/s11606-017-4171-2

Dyrbye, L. N., Thomas, M. R., \& Shanafelt, T. D. (2005). Medical student distress: Causes, consequences, and proposed solutions. Mayo Clinic Proceedings, 80(12), 1613-1622. https://doi.org/10.4065/80.12.1613

Dyrbye, L. N., Thomas, M. R., \& Shanafelt, T. D. (2006). Systematic review of depression, anxiety, and other indicators of psychological distress among U.S. and Canadian medical students. Academic Medicine, 81(4), 354-373. https://doi.org/10.1097/00001888-200604000-00009

Dyrbye, L. N., West, C. P., Satele, D., Boone, S., Tan, L., Sloan, J., \& Shanafelt, T. D. (2014). Burnout among u.s. medical students, residents, and early career physicians relative to the general u.s. population. Academic Medicine, 89(3), 443-451. https://doi.org/10.1097/ACM.0000000000000134

Flavell, J. H. (1979). Metacognition and cognitive monitoring: A new area of cognitivedevelopmental inquiry. American Psychologist, 34(10), 906. https://doi.org/10.1037/0003-066X.34.10.906

Frank, J. R., Snell, L., \& Sherbino, J. (Eds.). (2015). CanMEDS 2015. CanMEDS 2015 Physician Competency Framework. Ottawa: Royal College of Physicians and Surgeons of Canada, 1-30 http://www.royalcollege.ca/portal/page/portal/rc/canmeds/resources/publications

Freire, P. (1996). Pedagogy of the oppressed (revised). New York: Continuum.

Gagarin, M., \& Fantham, E. (Eds.). (2010). The Oxford Encyclopedia of Ancient Greece and Rome (Vol. 1). Oxford University Press on Demand.

Goffman, E. (1997). The Goffman Reader. Blackwell. 
Gofton, W., \& Regehr, G. (2006). What we don't know we are teaching: Unveiling the hidden curriculum. Clinical Orthopaedics and Related Research, 449, 20-27. https://doi.org/10.1097/01.blo.0000224024.96034.b2

Gross, N. (2009). A pragmatist theory of social mechanisms. American sociological review, 74(3), 358-379. https://doi.org/10.1177/000312240907400302

Gutiérrez, K. D. (2016). 2011 AERA Presidential Address: Designing Resilient Ecologies: Social Design Experiments and a New Social Imagination. Educational Researcher, 45(3), 187-196. https://doi.org/10.3102/0013189X16645430

Hafferty, F. (1998). Beyond Curriculum reform: Confronting Medicine's Hidden Curriculum. Academic Medicine, 73(4), 403-407. https://doi.org/10.1097/00001888-19980400000013

Hargreaves, K. (2016). Reflection in Medical Education. Journal of University Teaching \& Learning Practice, 13(2). https://doi.org/10.53761/1.13.2.6

Hill, M. R., Goicochea, S., \& Merlo, L. J. (2018). In their own words: stressors facing medical students in the millennial generation. Medical Education Online, 23(1). https://doi.org/10.1080/10872981.2018.1530558

Hojat, M., Nasca, T. J., Erdmann, J. B., Frisby, A. J., Veloski, J. J., \& Gonnella, J. S. (2003). An operational measure of physician lifelong learning: Its development, components and preliminary psychometric data. Medical Teacher, 25(4), 433-437. https://doi.org/10.1080/0142159031000137463

Hojat, M., Veloski, J. J., \& Gonnella, J. S. (2009). Measurement and Correlates of Physicians' Lifelong Learning. Academic Medicine, 84(8), 1066-1074. https://doi.org/10.1097/ACM.0b013e3181acf25f

Hu, K. S., Chibnall, J. T., \& Slavin, S. J. (2019). Maladaptive Perfectionism, Impostorism, and Cognitive Distortions: Threats to the Mental Health of Pre-clinical Medical Students. Academic Psychiatry, 43(4), 381-385. https://doi.org/10.1007/s40596-019-01031-z

Jackson, P. W. (1990). Life in classrooms. Teachers College Press.

Jarvis, P. (1999). The Practitioner-Researcher. Developing Theory from Practice. Jossey-Bass Higher and Adult Education Series. Jossey-Bass Publishers, 350 Sansome St., San Francisco, CA 94104.

Jarvis, P., Holford, J., \& Griffin, C. (2003). The theory \& practice of learning. Psychology Press. https://doi.org/10.4324/9780203465653

Jones, W. H. S. (1945). The Hippocratic Oath - Ludwig Edelstein: The Hippocratic Oath. Text, Translation, and Interpretation. Pp. vii+64. Baltimore: Johns Hopkins Press, 1943. Paper, \$1.25. The Classical Review, 59(1), 14-15 https://doi.org/10.1017/S0009840X00087515

Knowles, M. S. (1975). Self-directed learning: A guide for learners and teachers.

Kolb, D. A. (1984). Experiential Learning: Experience as the Source of Learning and Development. Prentice Hall.

Lempp, H., \& Seale, C. (2004). The Hidden Curriculum in Undergraduate Medical Education: Qualitative Study of Medical Students' Perceptions of Teaching. British Medical Journal, 329(7469), 767-770.

Lieff, S., \& Albert, M. (2012). What do we do? Practices and learning strategies of medical education leaders. Medical Teacher, 34(4), 312-319. https://doi.org/10.3109/0142159X.2012.643835 
Linscott, R. J., \& van Os, J. (2010). Systematic Reviews of Categorical Versus Continuum Models in Psychosis: Evidence for Discontinuous Subpopulations Underlying a Psychometric Continuum. Implications for DSM-V, DSM-VI, and DSM-VII. Annual Review of Clinical Psychology, 6(1), 391-419. https://doi.org/10.1146/annurev.clinpsy.032408.153506

MacArthur, K. R., \& Sikorski, J. (2020). A qualitative analysis of the coping reservoir model of pre-clinical medical student well-being: Human connection as making it "worth it." BMC Medical Education, 20(1), 1-11. https://doi.org/10.1186/s 12909-020-02067-8

Mackin, R., Baptiste, S., Niec, A., \& Kam, A. J. (2019). The Hidden Curriculum: A Good Thing? Cureus, 11(12), 1-6. https://doi.org/10.7759/cureus.6305

Mahood, S, C. (2011). The hidden curriculum. Canaidan Family Physician, 57(9), 983-985.

Marzo, R. R. (2018). Role of Medical Education in Cultivating Lifelong Learning Skills for Future Doctors. Education in Medicine Journal, 10(3), 63-66. https://doi.org/10.21315/eimj2018.10.3.7

Mi, M., \& Halalau, A. (2016). A pilot study exploring the relationship between lifelong learning and factors associated with evidence-based medicine. International Journal of Medical Education, 7, 214-219. https://doi.org/10.5116/ijme.576f.a2ca

Murakami, M., Kawabata, H., \& Maezawa, M. (2009). The perception of the hidden curriculum on medical education: an exploratory study. Asia Pacific Family Medicine, 8(1), 9. https://doi.org/10.1186/1447-056x-8-9

Nathan, M. J., \& Alibali, M. W. (2010). Learning sciences. Wiley Interdisciplinary Reviews: Cognitive Science, 1(3), 329-345. https://doi.org/10.1002/wcs.54

Owens, M. T., \& Tanner, K. D. (2017). Teaching as brain changing: Exploring connections between neuroscience and innovative teaching. CBE Life Sciences Education, 16(2), 19. https://doi.org/10.1187/cbe.17-01-0005

Oxford University Press. (2020). Knowledge. In Oxford Learner's Dictionary. Oxford University Press.

Paice, E., Heard, S., \& Moss, F. (2002). How important are role models in making good doctors? British Medical Journal, 325(7366), 707-710. https://doi.org/10.1136/bmj.325.7366.707

Piaget, J. (1976). Piaget's theory. In Piaget and his school (pp. 11-23). Springer, Berlin, Heidelberg. https://doi.org/10.1007/978-3-642-46323-5_2

Polanyi, M. (1983). The Tacit Dimension. Peter Smith. https://books.google.com/books?id=phQcAQAAMAAJ

Rotenstein, L. S., Ramos, M. A., Torre, M., Bradley Segal, J., Peluso, M. J., Guille, C., Sen, S., \& Mata, D. A. (2016). Prevalence of depression, depressive symptoms, and suicidal ideation among medical students a systematic review and meta-analysis. JAMA Journal of the American Medical Association, 316(21), 2214-2236. https://doi.org/10.1001/jama.2016.17324

Rotter, J. B. (1966). Generalized expectancies for internal versus external control of reinforcement. In Psychological Monographs: General and Applied (Vol. 80, Issue 1, pp. 1-28). American Psychological Association. https://doi.org/10.1037/h0092976

Sawyer, R. K. (2008). Optimising learning implications of learning sciences research. Innovating to Learn, Learning to Innovate, 9789264047, 45-65. https://doi.org/10.1787/9789264047983-4-en 
Scheffler, I. (1965). Conditions of Knowledge: An Introduction to Epistemology and Education. Scott, Foresman. https://books.google.com/books?id=ZCQQKoJ3FzoC

Schumacher, D. J., Englander, R., \& Carraccio, C. (2013). Developing the master learner: Applying learning theory to the learner, the teacher, and the learning environment. Academic Medicine, 88(11), 1635-1645. https://doi.org/10.1097/ACM.0b013e3182a6e8f8

Shaffer, D. W. (2004). Epistemic Frames and Islands of Expertise: Learning from infusion experiences. ICLS '04 Proceedings of the 6th International Conference on Learning Sciences, 473-480.

Slavin, S. (2016). Medical Student Mental Health: Culture, Environment, and the Need for Change. JAMA - Journal of the American Medical Association, 316(21), 2195-2196. https://doi.org/10.1001/jama.2016.16396

Slavin, S. (2018). Medical Student Mental Health: Challenges and Opportunities. Medical Science Educator, 28(1), 13-15. https://doi.org/10.1007/s40670-018-0622-6

Slavin, S, J., \& Chibnall, J. T. (2016). Finding the why, changing the how: Improving the mental health of medical students, residents, and physicians. Academic Medicine, 91(9), 1194-1196. https://doi.org/10.1097/ACM.0000000000001226

Slavin, S., Schindler, Debra, L., \& Chibnall, John, T. (2014). Medical student mental health 3.0: Improving student wellness through curricular changes. Academic Medicine, 89(4), 573-577. https://doi.org/10.1097/ACM.0000000000000166

Sockalingam, S., Soklaridis, S., Yufe, S., Rawkins, S., Harris, I., Tekian, A., Silver, I., \& Wiljer, D. (2017). Incorporating lifelong learning from residency to practice: a qualitative study exploring psychiatry learners' needs and motivations. Journal of Continuing Education in the Health Professions, 37(2), 90-97. https://doi.org/10.1097/CEH.0000000000000156

Sockalingam, S., Tavares, W., Charow, R., Youssef, A., Campbell, C., Davis, D., Giuliani, M., Okrainec, A., Papadakos, J., Silver, I., \& Wiljer, D. (2019). Examining Associations Between Physician Data Utilization for Practice Improvement and Lifelong Learning. The Journal of Continuing Education in the Health Professions, 39(4), 236-242. https://doi.org/10.1097/CEH.0000000000000268

Sood, A., Prasad, K., Schroeder, D., \& Varkey, P. (2011). Stress management and resilience training among department of medicine faculty: A pilot randomized clinical trial. Journal of General Internal Medicine, 26(8), 858-861. https://doi.org/10.1007/s11606011-1640-x

Sood, A., Sharma, V., Schroeder, D. R., \& Gorman, B. (2014). Stress Management and Resiliency Training (SMART) program among department of radiology faculty: A pilot randomized clinical trial. Explore: The Journal of Science and Healing, 10(6), 358363. https://doi.org/10.1016/j.explore.2014.08.002

Teunissen, P. W., \& Dornan, T. (2008). The competent novice: Lifelong learning at work. Bmj, 336(7645), 667-669. https://doi.org/10.1136/bmj.39434.601690.AD

Tjia, J., Givens, J. L., \& Shea, J. A. (2005). Factors associated with undertreatment of medical student depression. Journal of American College Health, 53(5), 219-224. https://doi.org/10.3200/JACH.53.5.219-224

Tokuhama-Espinosa, T. (2017). Elegant Complexity: The Theory of the Five Pillars of Neuoconstructivism in the Brain. Harvard University Extension School, Latin American Faculty for Social Science Research. 
Tokuhama-Espinosa, T. (2019). The Learning Sciences Framework in Educational Leadership. Frontiers in Education, 4(December). https://doi.org/10.3389/feduc.2019.00136

Vygotsky, L. (1978). Mind in society: The development of higher psychological processes. L. S. Vygotsky. In M. Cole, V. John-Steiner, S. Scribner, \& E. Souberman (Eds.), Mind in society: The development of higher psychological processes. L. S. Vygotsky. Harvard U Press.

Ward, S., \& Outram, S. (2016). Medicine: In need of culture change. Internal Medicine Journal, 46(1), 112-116. https://doi.org/10.1111/imj.12954

Watson, K. M. (2019). The Operationalization of Integrated Internal Action Frameworks for Classroom Identity Development and Self-regulating Learners. The European Journal of Social \& Behavioural Sciences, 25(2), 2948-2976. https://doi.org/10.15405/ejsbs.257

Wenger, E. (1998). Communities of practice: Learning, meaning, and identity. In Communities of practice: Learning, meaning, and identity. Cambridge University Press. https://doi.org/10.1017/CBO9780511803932

Wetzel, A. P., Mazmanian, P. E., Hojat, M., Kreutzer, K. O., Carrico, R. J., Carr, C., Veloski, J., \& Rafiq, A. (2010). Measuring medical students' orientation toward lifelong learning: A psychometric evaluation. Academic Medicine, 85(10 SUPPL.), 41-44. https://doi.org/10.1097/ACM.0b013e3181ed1ae9

Wilkes, C., Lewis, T., Brager, N., Bulloch, A., MacMaster, F., Paget, M., Holm, J., Farrell, S. M., \& Ventriglio, A. (2019). Wellbeing and mental health amongst medical students in Canada. International Review of Psychiatry, 31(7-8), 584-587. https://doi.org/10.1080/09540261.2019.1675927

Winne, P. H. (1996). A metacognitive view of individual differences in self-regulated learning. Learning and Individual Differences, 8(4), 327-353. https://doi.org/10.1016/S10416080(96)90022-9

World Health Organization. (2017). Depression and other common mental disorders: Global health estimates. https://apps.who.int/iris/bitstream/handle/10665/254610/WHOMSD-MER-2017.2-eng.pdf.

Zorek, J. A., Sprague, J. E., \& Popovich, N. G. (2010). Bulimic learning. American Journal of Pharmaceutical Education, 74(8), 1-3. https://doi.org/10.5688/aj7408157 